\title{
Investigation of Structural Steel Webs for Punching
}

\section{Shear}

\author{
Mustafa Mahamid $^{1}$ and Adeeb Rahman ${ }^{2}$ \\ 1. Department of Civil and Material Engineering, University of Illinois at Chicago, Chicago IL 60604,, USA \\ 2. Department of Civil Engineering and Mechanics, University of Wisconsin Milwaukee, Milwaukee WI 53201, USA
}

\begin{abstract}
Shear tab connections or simple connections are widely used in structural steel structures. There are several limit states associated with these connections such bolt shear, bolt bearing, block shear, shear yielding and shear rupture. A modified version of the shear tab has been developed during the last decade, which is extended shear tab connections. In developing design provisions for the extended shear tab connections, experimental work showed that there are additional limit states other than those mentioned above that limit the capacity of the extended shear connection. Extended shear tab connections could be used to frame beam-to-column or beam-to-girder. In the case where a beam is framed into girder, a new limit state develops in the web of the supporting girder. This limit state is punching shear of the supporting girder web which is due to a higher moment. The higher moment in extended shear tab connections is due to the larger moment arm (eccentricity) from the bolt line, the location of the shear force, to the support, which is in this case the girder's web. This study investigates the supporting girder web using experimental work, finite element analysis, and yield line theory. This paper shows the result of this investigation and proposes an evaluation of the web capacity equation which should be used when calculating the beam-to-girder connection capacity.
\end{abstract}

Key words: Steel connections, extended shear tab, punching shear, yield line, beam web limit states.

\section{Introduction}

The purpose of using the yield line theory in this work is to analyze steel shear tab connections' supporting members based on the distribution of the yield lines. Shear tabs are commonly used in steel structures. Standard shear tabs are made of relatively short steel plates, to reduce the eccentricity between the steel plate and the supporting member, which should reduce the moment applied to the supporting member. The disadvantage in using standard shear tab connections is that the connected beam normally has to be coped, which is an expensive process. Additionally, with the advent of technology, building geometries are becoming more complex and typical framing is not possible in all cases. Therefore, this connection option is becoming feasible and widely

Corresponding author: Mustafa Mahamid, Ph.D., S.E., P.E., clinical associate professor, research fields: structural engineeing and computational mechanics. E-mail: mmahamid@uic.edu. used to allow simplified framing and fabrication. Extended shear tabs circumvent that problem, since the bolt line is already beyond the flange of the girder. The extended shear tab connections have been introduced to practice for the first time in the AISC (American Institute of Steel Construction) manual 13th edition [1]. However, the disadvantage in this solution is the relatively high moment on the supporting member due to the large moment arm which produces larger torsional moment on the supporting girder and, as a result, increases the stresses in the supporting girder's web in addition to other stresses due to transferred shear force and any additional stresses due to other possible loads on the girder. Due to the high moment generated, the web of the supporting girder experiences deterioration and failure mechanism as was observed in experiments [2].

To bear the moment generated on the girder, these shear tabs are welded to the top flange of the girder as 
one solution and/or increase the girder's web thickness. One of the solutions would also be adding a stiffener to the back of the web. However, the main objective of this connection is to simplify the detailing. Therefore, adding a stiffener is not the best solution to this connection configuration. Additionally, extending the shear tab to the bottom flange would prevent the mechanism in the web, but experimental work by Sherman and Ghorbanpoor [2] showed that buckling would occur in the shear tab at a much reduced capacity of the connection.

Yield-line theory analysis approach has been used extensively in concrete structures and in particular in the analysis of reinforced concrete slabs [3]. Studies on thin webs and their plastic behavior have been performed in previous studies as indicated in Refs. [4-7]: These studies focused mainly on plate girders at which the capacity if mainly controlled by the web behavior. No research has been done on supporting member webs supporting beams using extended shear tab connections and girder's webs were never investigated as a limited state. The objective of this study is using the yield line approach to determine a supporting member's web capacity equation for the web mechanism limit state in the supporting girders. In doing so, first, the derivation of $k$-factors, which depend on the boundary conditions of the plate [2] for standard shear tabs will be verified. Due to the fact that the finite element analysis does not have the effect of residual stresses developed in the web of the girder, the actual tested connections are used to determine the yield-line pattern. The residual stresses developed in the girder are due to the fact of being a rolled section and due to the stresses developed during the welding process.

2. Background on Yield-Line Theory as Applied to Supporting Webs of Steel Sections

The yield-line theory is a method to determine ultimate loads for two dimensional members. It is based on energy equilibrium, which means that the external energy of the considered member must be equal to its internal energy. The external energy is the amount of work that is introduced by an external force, such as an evenly distributed floor load or, like in our case, a single bracket moment. The internal energy is the amount of work which is dissipated by the considered structural member under a special failure mode: The special failure mode is defined as the failure mode with the lowest energy dissipation. The simplest way to determine the minimum internal energy is to try several failure modes and compare their internal energy. The ultimate bearable load or moment can be obtained by using the energy equilibrium.

In our special case, Abolitz and Warner [8] derived Eqs. (1) and (2) below for ultimate moments based on elastic analysis as well as a more economical and, therefore, more accurate analysis, based on plastic analysis. The procedure developed in Ref. [8] is based on the yield-line pattern developed in the supporting member's web, as shown in Fig. 1.

Eqs. (1) and (2) can be described as follows:

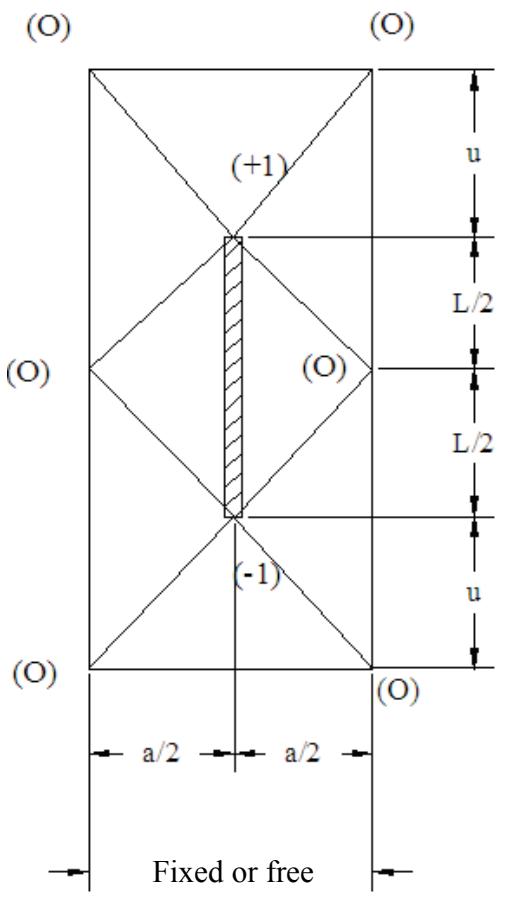

Fig. 1 Yield-line pattern. 


$$
X=\phi k m l
$$

where:

$X$ : the bracket moment;

$\phi$ : a safety factor;

$l$ : the height or the depth of the shear tab;

$k$ : 9.66 for free edges and 14 for fixed edges [8];

$m$ : the allowable moment in the plate, which is in the total plastic case:

$$
m=f s=(l / 4) f t^{2}
$$

where:

$f$ : the allowable bending stress of the used steel (All the terms are with respect to the old ASD (allowable stress design) method and not to the LRFD (load and resistance factored design));

$s$ : plate section modulus;

$t$ : the thickness of the structural member web;

$l$ : the height or the depth of the shear tab;

$m$ : the allowable moment in the plate, which is in the total plastic case.

In this study, the procedure described above is applied to the connection configuration which is shown in Fig. 2. Experiments by Sherman and Ghorbanpoor [2] and finite element analysis by Rahman et al. [9] and Mahamid et al. [10] showed that a mechanism is developed in the web of the girder (Beam A) as a result of loads applied to the supported beam (Beam B).

\section{Development of Supporting Girder Web Capacity Equation from Test Data}

Due to the unevenly distributed residual stresses, the data were obtained from test measurements and plots. The kinks in the plots, as shown in the following figures, can be used as a yield criterion. Since it is not possible to fit an exact curve to the deformation plot and account for the sudden changes in the slope, and since the sudden changes in the deformation plots have to be investigated, other ways like calculating the curvature from the deflection curve (2nd derivative) and check the curve for that yield criterion are not feasible.

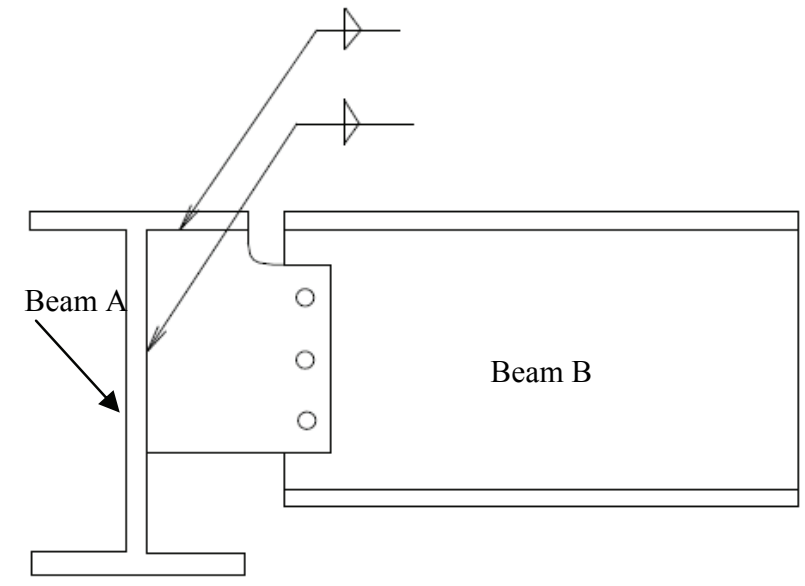

Fig. 2 Beam-to-girder extended shear tab connection.

The kinks (sudden changes) in the deformation plots can then be connected to form yield lines. In yield-line theory, it is assumed that all rotational deformations are concentrated in the yield lines and the planes do not have other deflections.

The actual tests on beams with attached shear tabs have been already carried out by Sherman and Ghorbanpoor [2] and analyzed analytically using non-linear finite element method by the authors [10], complete information about these tests prior to this investigation can be obtained from Refs. [2, 10]. The relatively small shear tab is attached with double filled welds, locally concentrated to a web which has a high in-plane stiffness that leads to considerably high residual stresses in addition to the residual stresses that already exist in the web of the girder due to the rolling process. Therefore, exact measurements of the web of tested girders have been carried out to determine the form of the web deformation. Using these data, a capacity equation will be developed and then the same method used above is used to estimate the ultimate moment on the girder's web. Four different connections with different shear tab dimensions and girder sizes are considered.

Four types of connections are investigated: three-, five-, six- and eight-bolted connections. These connections are designated as $1 \mathrm{~B}, 2 \mathrm{~B}, 5 \mathrm{~B}$, and $7 \mathrm{~B}$ respectively as shown in Table 1 . The dimensions of the girders, the shear tab and the number of bolts for 
the connections are shown in Fig. 3. A first inspection showed that the deflections are relatively small. A LVDT (Linear Variable Differential Transformer) with an ability to measure 1/1,000 of an inch has been used for the measurement. To get an accurate reference plane and grid for scanning the web area, a milling machine has been used. Furthermore, the girders were sand blasted and cleaned from welds as shown in Figs. 3 and 4. The girder is clamped on a movable table: The LVDT is fixed at the milling machine. This makes it possible to scan the web surface precisely. Figs. 5 and 6 show the measurement grid and it is observed that the grid is denser in the area close to the tip of the shear tab.

Table 1 Girder sizes and connection type.

\begin{tabular}{llll}
\hline Experiment & Girder & $\begin{array}{l}\text { Shear tab } \\
\text { thickness (in.) }\end{array}$ & $\begin{array}{l}\text { Connection } \\
\text { type }\end{array}$ \\
\hline $1 \mathrm{~B}$ & $\mathrm{~W} 14 \times 53$ & $1 / 4$ & 3 bolts \\
$2 \mathrm{~B}$ & $\mathrm{~W} 24 \times 55$ & $1 / 4$ & 5 bolts \\
$5 \mathrm{~B}$ & $\mathrm{~W} 30 \times 173$ & $5 / 16$ & 6 bolts \\
$7 \mathrm{~B}$ & $\mathrm{~W} 33 \times 152$ & $5 / 16$ & 8 bolts \\
\hline
\end{tabular}

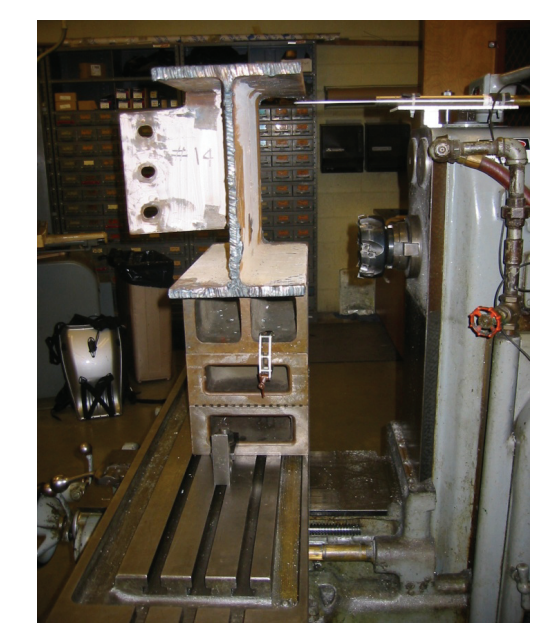

Fig. 3 Web measurements setup.

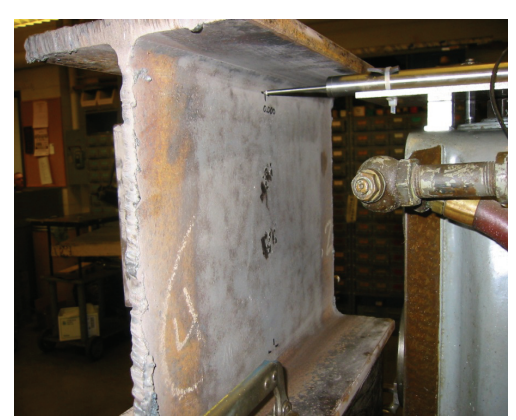

Fig. 4 Cleaned web with LVDT at the staring position.
The same procedure for sample preparation and measurements performed on Tests $1 \mathrm{~B}$ and $2 \mathrm{~B}$ is performed on Tests $5 \mathrm{~B}$ and $7 \mathrm{~B}$.

\section{Results}

All measurement data have been taken and recorded in an excel spreadsheet. For Test 1B, the raw data apparently showed a small rotational error with respect to the vertical axis or the depth of the girder. This error has been fixed with a correction factor. Fig. 7 shows the deformation in the girder on the vertical axis ( $y$-axis, along the depth of the girder) with respect to locations along the girder's web longitudinal axis ( $x$-axis): The figure shows that the deformations decrease with increasing distance from the shear tab. It is noticed that the web deflects in its highest values in the area of the bottom edge of the shear tab. Fig. 8 shows that the deformations are almost perfectly symmetric with respect to the vertical symmetrical axis (location of shear tab). Fig. 9 shows the deformation at different $y$ locations (along the depth of the girder's web): Symmetry is also observed in this figure.

Fig. 10 shows the contours of the deformations of the web of the girder. The figure shows the kinks in the contours which indicate a concentrated change in the deformation which can be identified as a yield-line path. The three-dimensional contour plot is shown in Fig. 11 and shows a conical shape with its tip above the shear tab bottom edge. The deformations do not just show a local effect in the direct vicinity of the bottom of the shear tab but also die out in each direction relatively and smoothly. The yield-line pattern can now be derived by connecting these kinks to a pattern of yield lines as shown in Fig. 12 for Test $1 \mathrm{~B}$ and Fig. 13 for Test 2B, and similar results were obtained for Tests $5 \mathrm{~B}$ and $7 \mathrm{~B}$. The yield line pattern is shown clearly in Fig. 14.

In this pattern, the assumed yield lines are extended until they hit the girder's fillets. Calculating the angles and the lengths shown in Fig. 14 using AutoCAD, the 


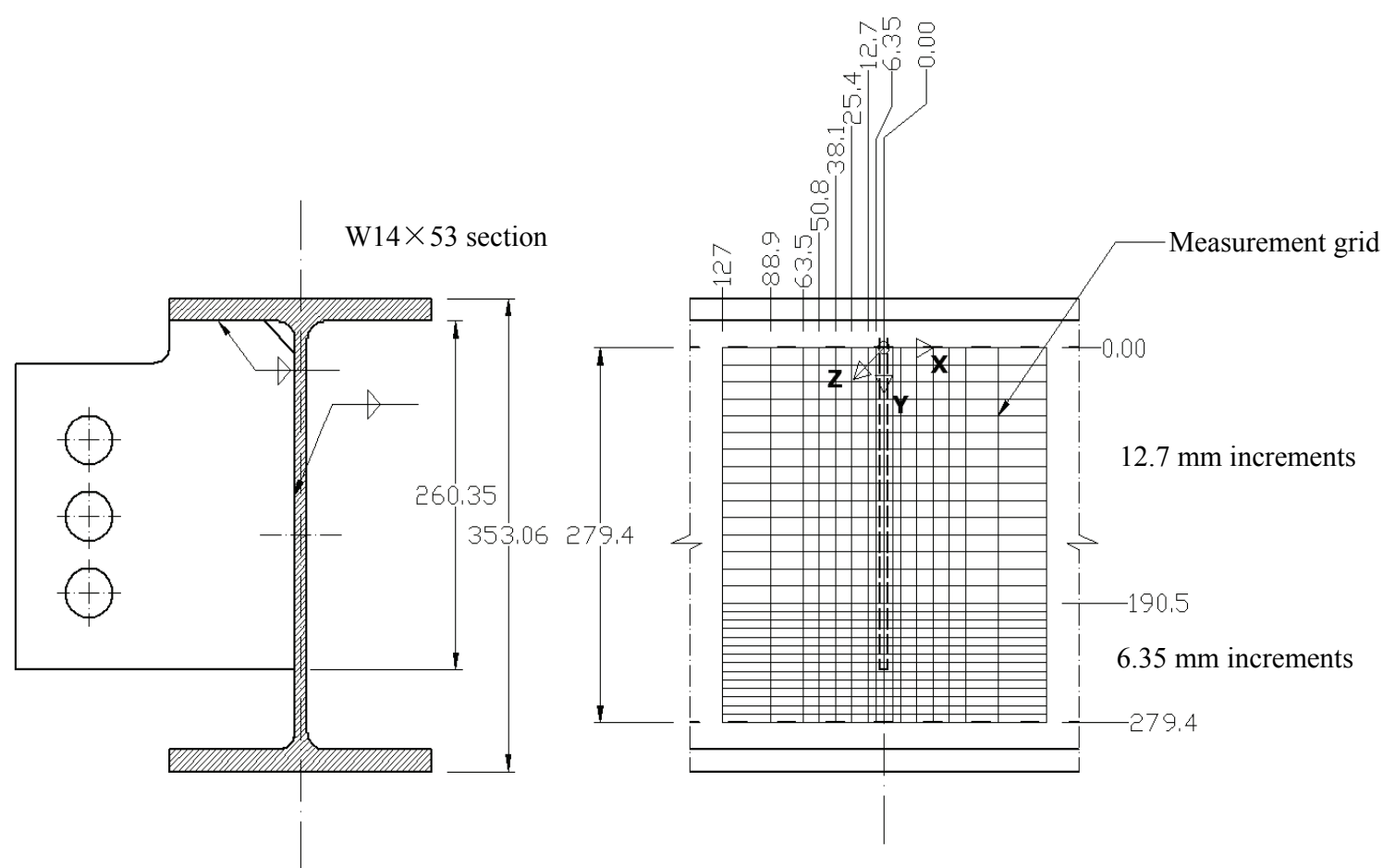

Fig. 5 Measurement grid for Test 1B (units in inches).

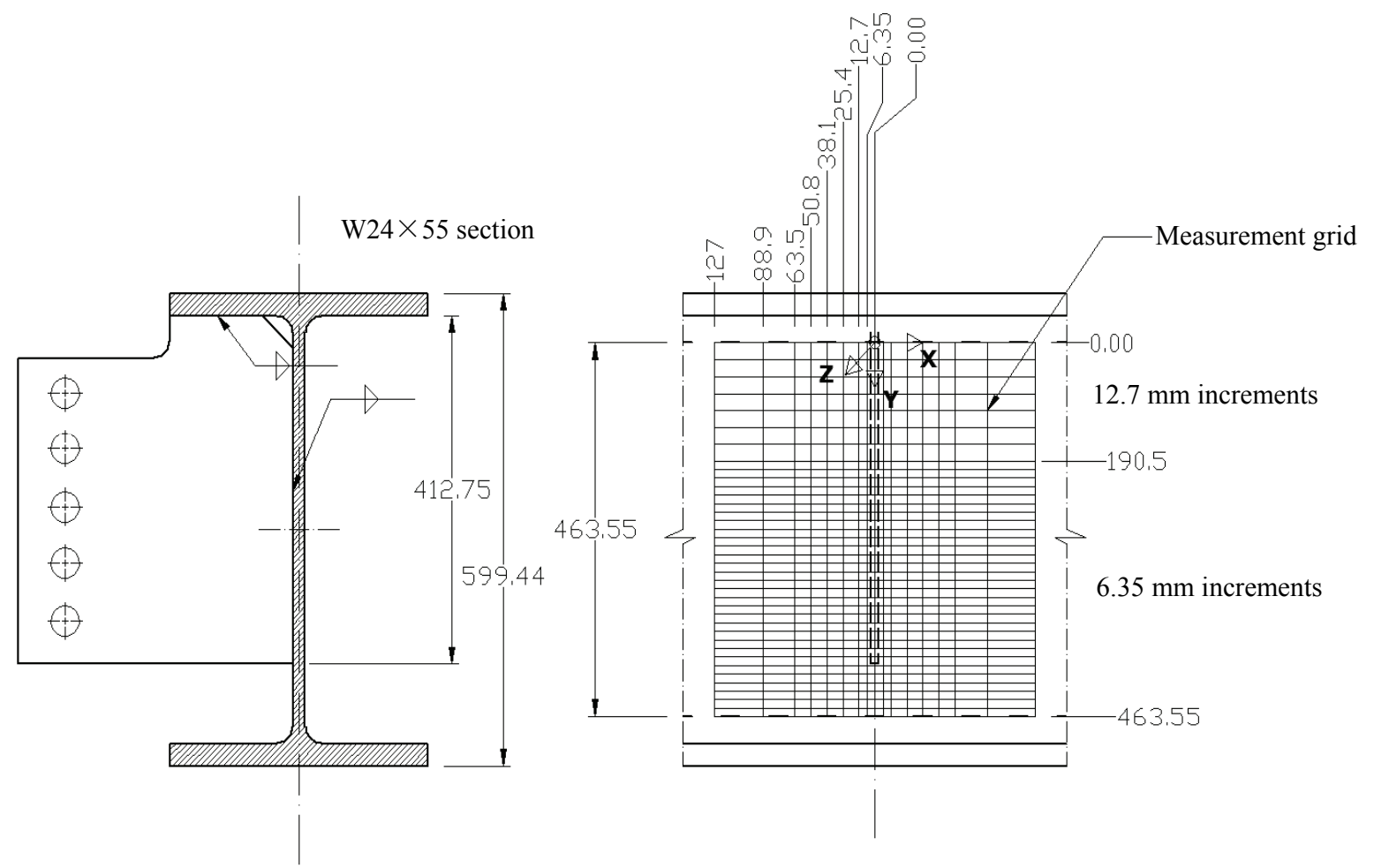

Fig. 6 Measurement grid for Test 2B (units in inches). 


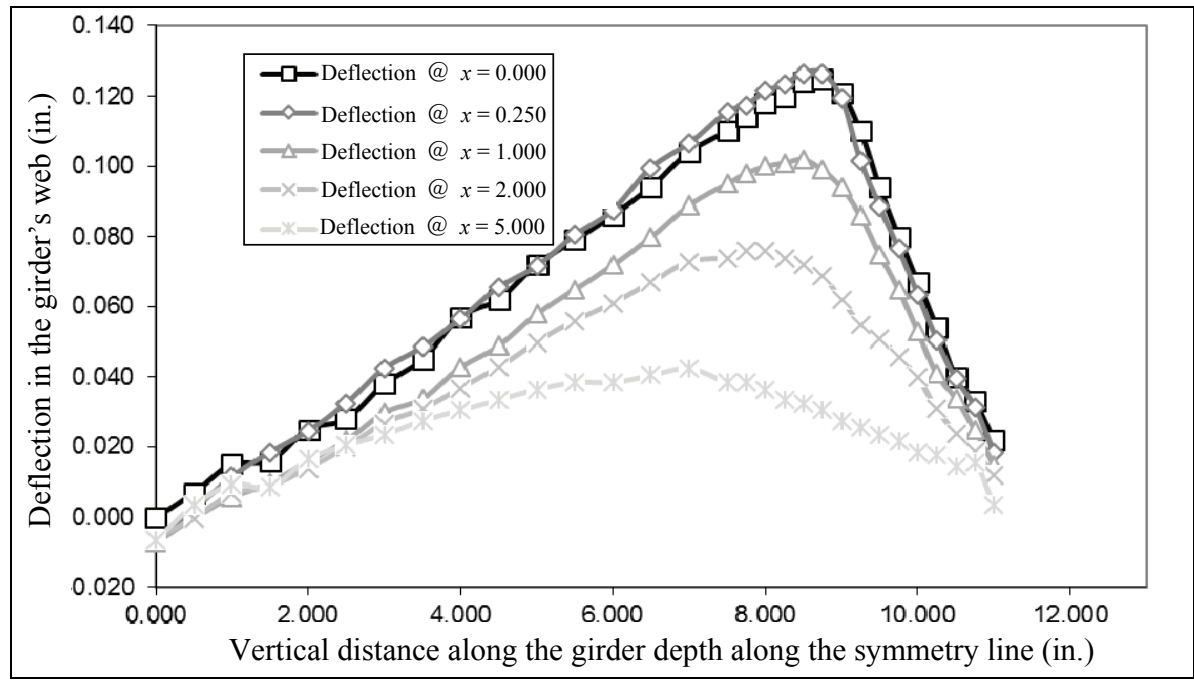

Fig. 7 Deformation of the girder's web along its depth (y-axis) at different horizontal locations ( $x$-axis) on one side from the symmetry line.

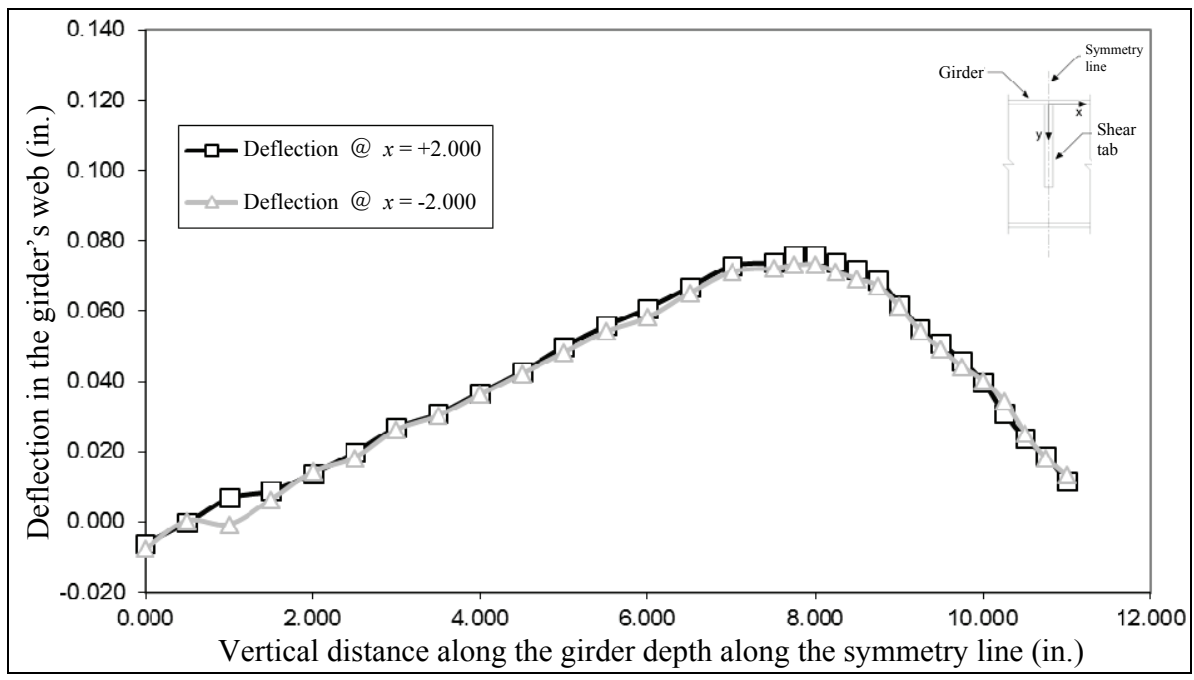

Fig. 8 Deformation of the girder's web along its depth (y-axis) measured horizontally at $x=+2.0$ in. and $x=-2.0$ in. from the symmetry line.

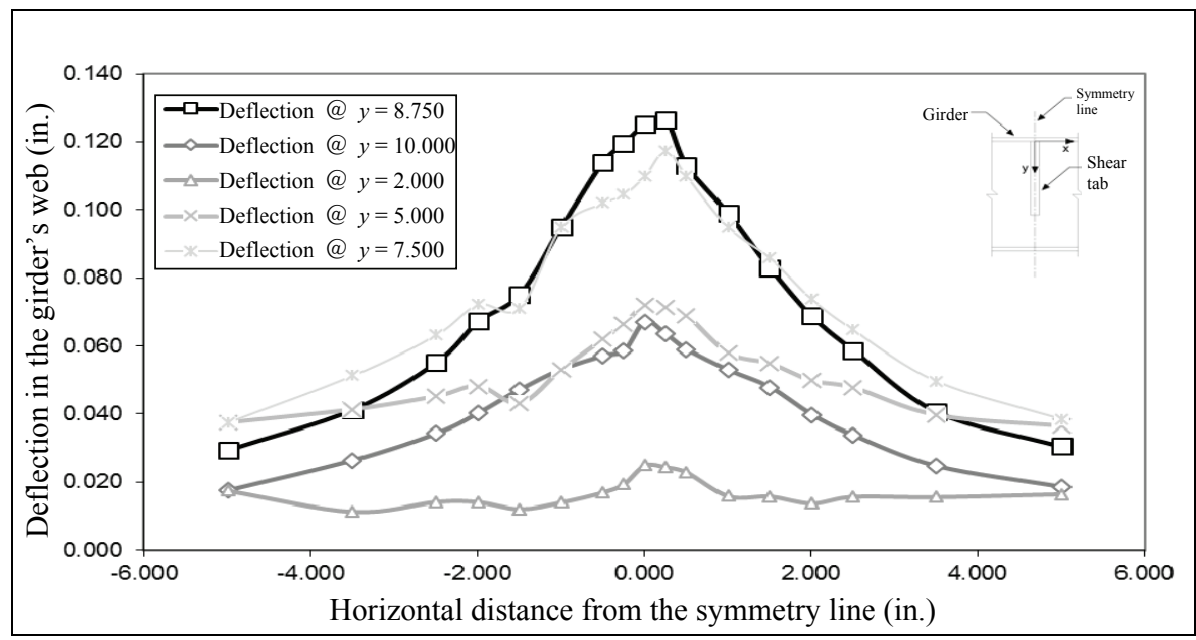

Fig. 9 Deformation of the girder's web along its horizontal locations ( $x$-axis) measured at different depth (y-axis) from the symmetry line. 


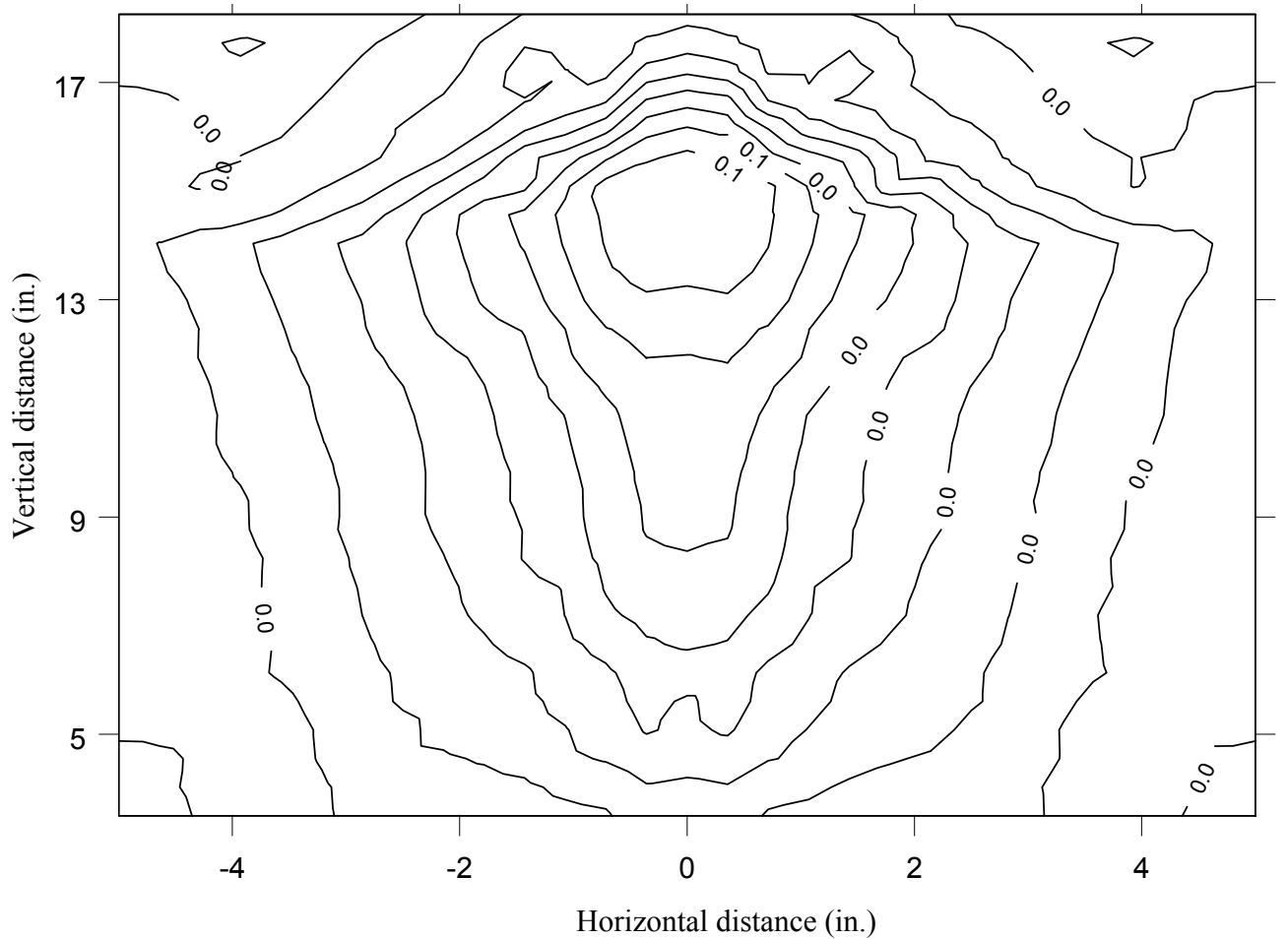

Fig. 10 Two-dimensional contour plot of the web deformation.

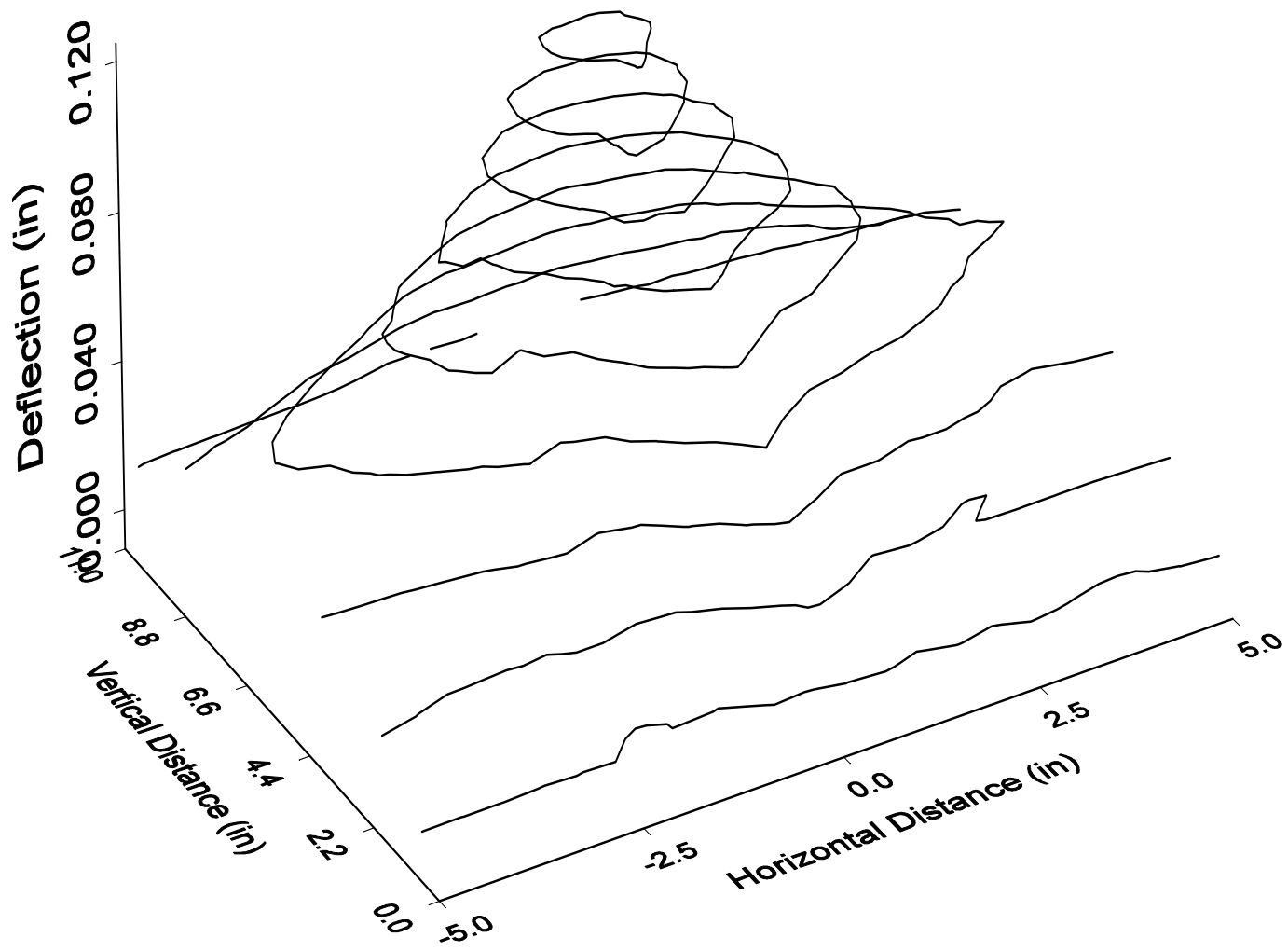

Fig. 11 Three-dimensional contour plot of the web deformation. 


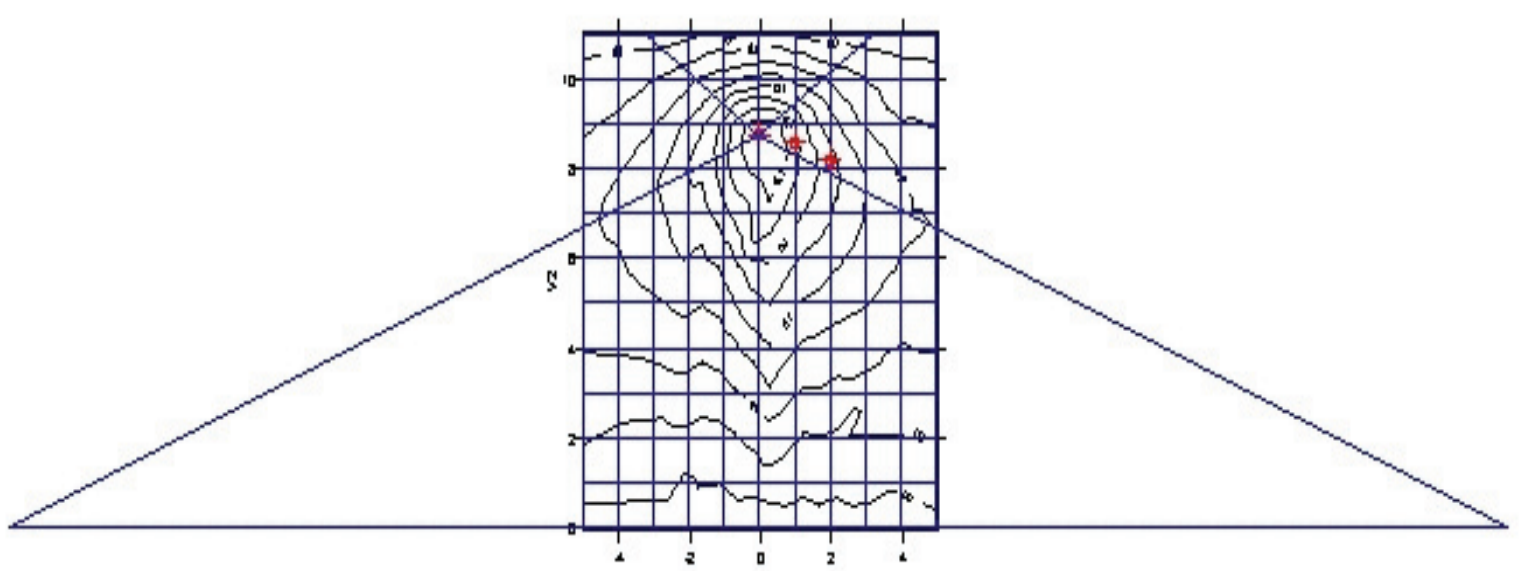

Fig. 12 Yield-line patter for girder's web for Test 1B.

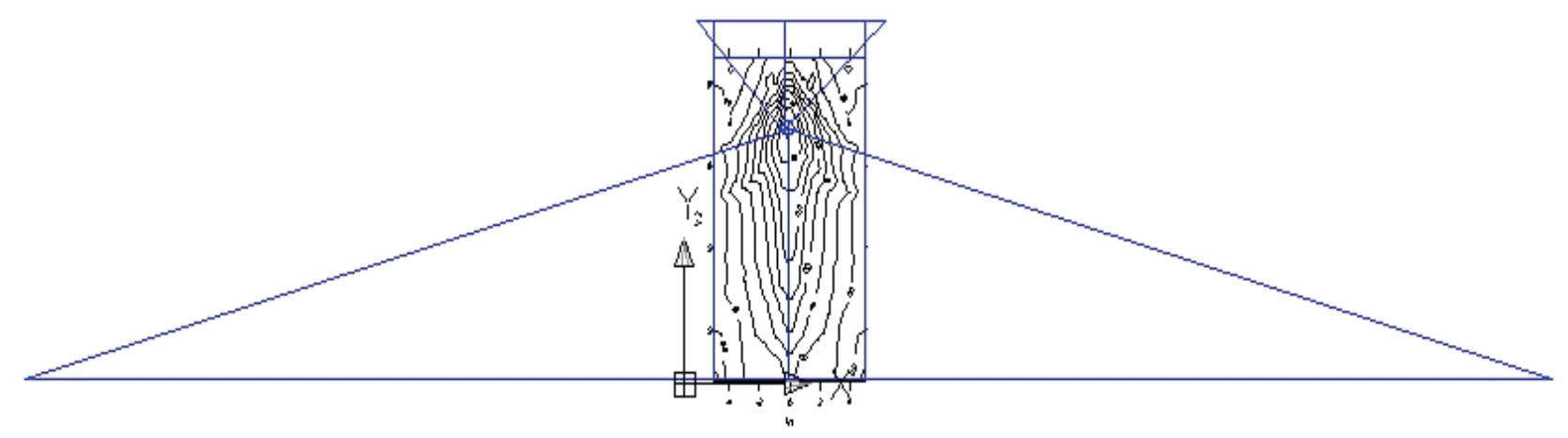

Fig. 13 Yield-line pattern for girder's web for Test 2B.

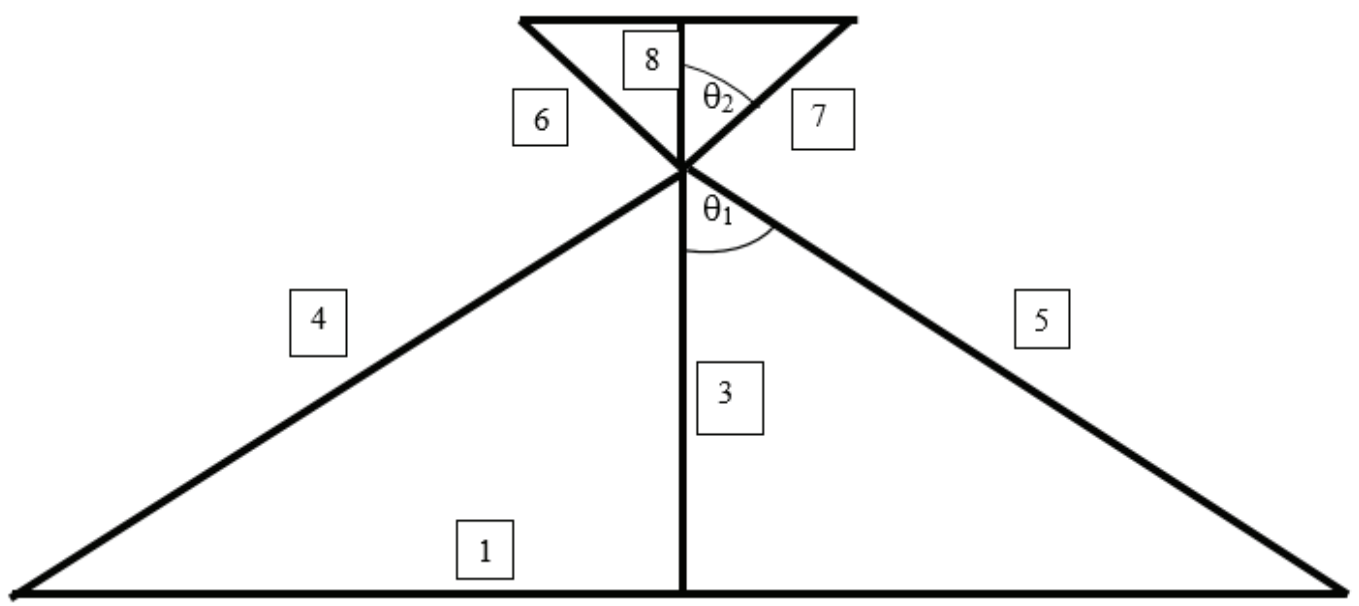

Fig. 14 Yield-line pattern in girders' webs.

external energy can be summed and equated to the internal energy, as shown in Eq. (4):

$$
\Pi_{(\mathrm{e})}=\Pi_{(\mathrm{i})}
$$

The capacity of the web of the girder is calculated based on Eq. (4) of the AISC Hollow Structural
Sections Connection Manual [11] and shown in Eq. (5):

$$
R=k \frac{t^{2} F_{y} l}{4 e}
$$

where:

$R$ : capacity of the girder; 
$k$ : factor calculated according to the procedure developed in this study;

$t$ : thickness of the girders' web;

$F_{y}$ : yield strength of the web;

$l$ : length of the shear tab;

$e$ : distance from bolt line to the girder's web.

Test measurements and energy calculations are performed for all tests: The results of the calculations are presented in Table 2. Table 2 shows the moment capacity of the girders, the calculated shear capacity of the connection and the failure modes in each test. The table shows that the calculated values are higher than the maximum values applied. This is due to the fact that web mechanism was not considered a primary failure mode in these connections.

\section{Extension on the Test Measurements to Include Other Steel Sections}

Based on the results presented above, a yield-line pattern is developed in the girder as shown in Fig. 14. Relations between the shear tab length and the yield lines are investigated and derived as shown in
Figs. 15-17. Fig. 15 shows a relation between the shear tab length and YL3 (Yield Line 3). For the connections with six bolts, the length of YL3 is approximately the same as the shear tab length because the maximum deformation in the web occurs at the lower tip of the shear tab. However, for deeper connections, the shear tab deteriorates at high loads and the maximum deformation in the web of the girder does not occur at the tip of the shear tab: The length of YL3 is less than the shear tab length. The measurements described above are for connections up to eight bolts. However, finite element analysis performed by Mahamid et al. [10] for connections up to 12 bolts. The finite element models [10] for 10- and 12-bolted connections show that deterioration occurs also at the bottom of the shear tab and the maximum deformation in the web of the girder occurs at length less than the length of the shear tab. The relationships between the different yield lines, the angles and the shear tab length are shown in Figs. 15-18.

The break in the curve occurs when the deterioration occurs at the bottom of the shear tab.

Table 2 Yield line and experimental girders' capacities and failure modes.

\begin{tabular}{lllllll}
\hline Experiment & \multirow{2}{*}{ Girder } & $\begin{array}{l}\text { Web bracket } \\
\text { moment (kip-ft) }\end{array}$ & $\begin{array}{l}\text { Maximum applied bracket } \begin{array}{l}\text { LRFD shear } \\
\text { moment (kip-ft) }\end{array} \\
\text { capity } R(k i p)\end{array}$ & $\begin{array}{l}\text { Maximum applied } \\
\text { shear (kip) }\end{array}$ & Failure modes \\
\hline 1B & W14 $\times 53$ & 37.8 & 37 & 55.93 & 54.6 & C (F and B) \\
2B & W24 $\times 55$ & 64.77 & 61.73 & 96.93 & 92.6 & C (F and B) \\
5B & W30 $\times 173$ & 182 & 141 & 183.76 & 140.7 & B, C, A (E) \\
7B & W33 $\times 152$ & 204.4 & 191.5 & 238.1 & 224.2 & F, C (B, E and K) \\
\hline
\end{tabular}

$\mathrm{A}=$ bolt shear; $\mathrm{B}=$ bolt bearing; $\mathrm{C}=$ shear yield; $\mathrm{D}=$ shear rupture; $\mathrm{E}=$ web mechanism; $\mathrm{F}$ = twist; $\mathrm{G}=$ weld; $\mathrm{H}=$ plate buckling; $\mathrm{I}=$ tearing; $\mathrm{J}=$ bolt fracture; $\mathrm{K}=$ web shear.

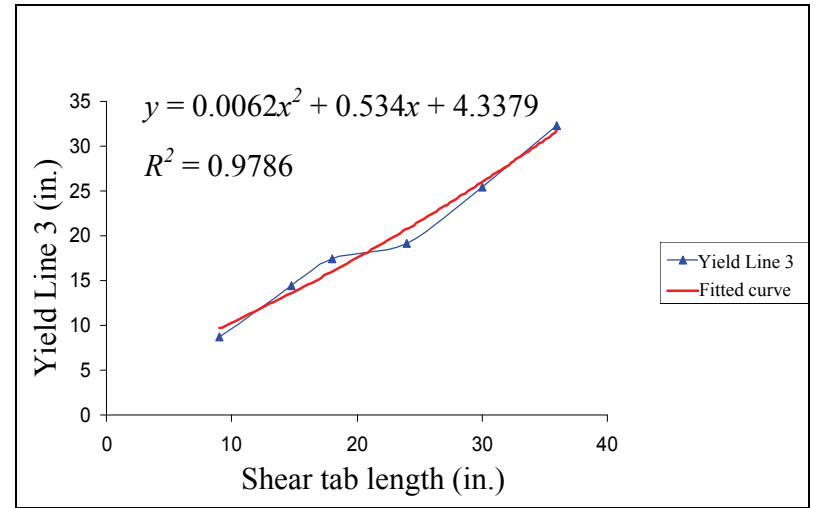

Fig. 15 Yield Line 3 vs. shear tab length.

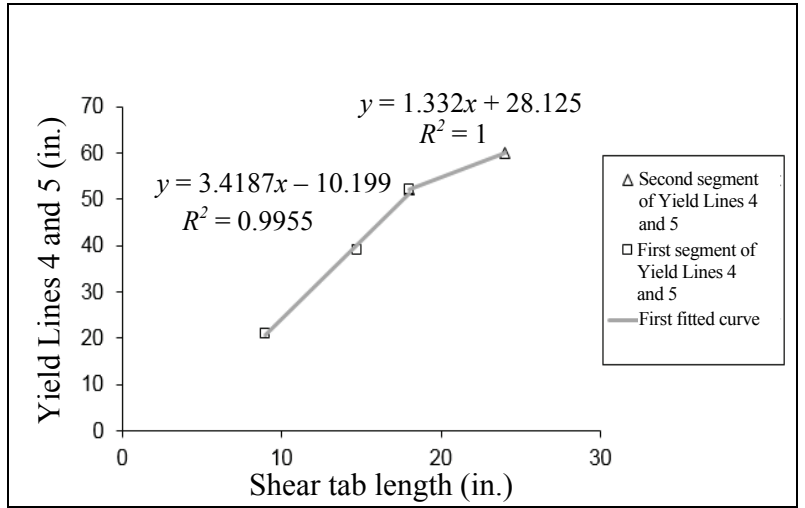

Fig. 16 Yield Lines 4 and 5 vs. shear tab length. 


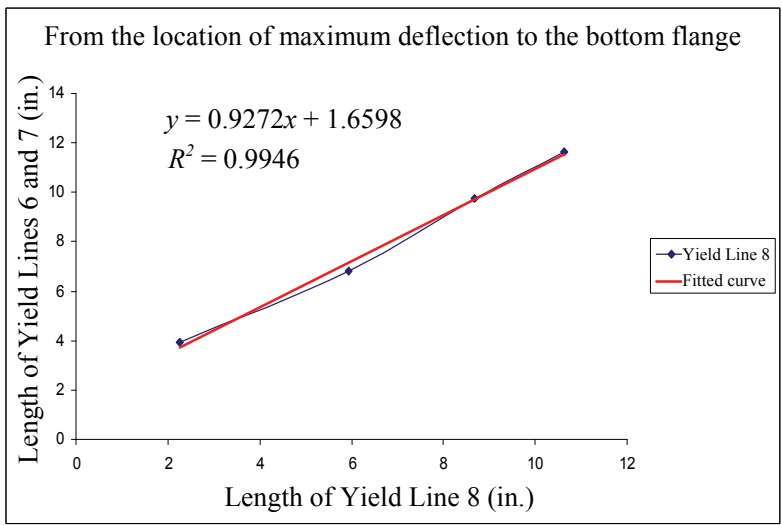

Fig. 17 Yield Lines 6 and 7 vs. Yield Line 8.

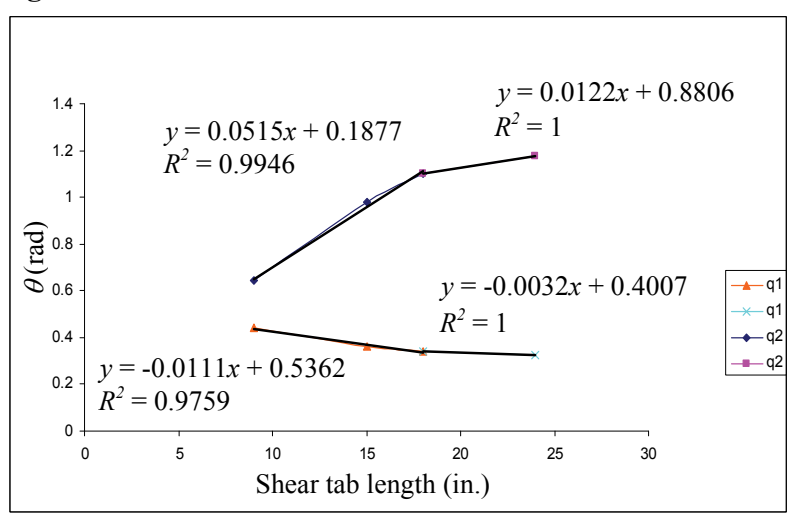

Fig. 18 Shear tab length vs. $\theta_{1}$ and $\theta_{2}$.

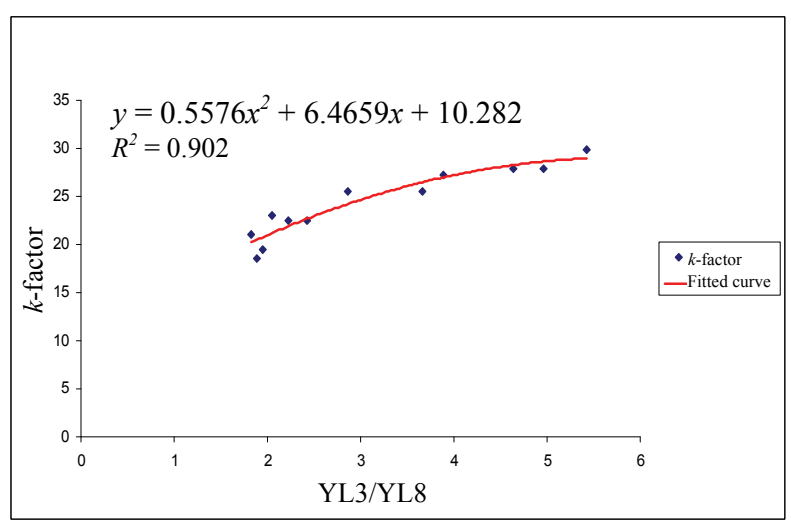

Fig. 19 The $k$-factor vs. YL3/YL8.

The angles $\theta_{1}$ and $\theta_{2}$ are also investigated and relationships between the shear tab length and the angles are derived, as shown in Fig. 18. It is obvious that each curve in Fig. 18 has two segments: The break in the curves is mentioned above due to the deterioration of the bottom of the shear tab.

According to the relations obtained from yield lines, test measurements, and from finite element analysis, a flowchart was developed to create any yield-line pattern with the appropriate lengths for any girder and connection configuration. The $k$-factor for all these cases, which is used in Eq. 4-21a of the AISC Hollow Structural Sections (HSS) Connection Manual [11] to calculate the capacity of the girder, is shown in Fig. 19. $k$-factor is used in. An equation for $k$-factor is derived from curve fitting, as shown in Fig. 19. It is observed that there is a relation between $k$-factor and the ratio of YL3/YL8. A good correlation of $90 \%$ is obtained from curve fitting. A good correlation between the finite element models used and the experimental results was shown in previous work published in Engineering Journal by Rahman et al. [9] and Mahamid et al. [10].

\section{Procedure for the Determination of $k$-Factor}

To determine $k$-factor and the corresponding girders' capacity, the following procedure is recommended:

- Find the length of YL8 based on shear tab length determine the length of YL3:

$$
Y L 8=h-Y L 3
$$

where, $h$ is the depth of the web of the girder;

- Find the ratio $m=Y L 3 / Y L 8$;

- Find $k$-factor from the following equation:

$$
k=-0.56 m^{2}+6.5 m+10.3
$$

- Substitute $k$ in Eq. (5) to find the capacity of the girder;

- Find the capacity of a W36 $\times 230$ girder welded to a 10-bolted shear tab connection of a depth of $l=$ 30 in., Girder W36 $\times 230$ : web slenderness $h / t w=$ 41.4, web thickness $t w=0.76$ in., web depth $h=31.46$ in., $n=10$ bolts, $l=30 \mathrm{in}$., steel yield strength $F y=50$ ksi, $e=12.37$ in.:

(1) Find the length of YL3:

$Y L 3=0.0062 l^{2}+0.531+4.34=0.0062 \times 30^{2}+$ $0.53 \times 30+4.34=25.94$

(2) Find the length of YL8:

$Y L 8=h-Y L 3=31.46-25.94=5.524$ in.

(3) Find the ratio $m=Y L 3 / Y L 8=25.94 / 5.524=4.70$; 
(4) $k=-0.56 m^{2}+6.5 m+10.3=-0.56 \times 4.7^{2}+6.5 \times$ $4.7+10.3=28.48$;

(5) $R=k \frac{t^{2} F_{y} l}{4 e}=28.48 \frac{(0.76)^{2}(50,000)(30)}{4(12.37)}$ $=498.7 \mathrm{kips}$

\section{Conclusions}

The experimental and the finite element investigations led to deriving a factor that is used in Eq. 4-21a of the AISC Hollow Structural Sections Connection Manual [11] to determine the girders' capacity when subjected to high moments due to beam reaction and a distance from the bolt line to the weld line when supporting an extended shear tab connection. Similar procedure is used for determining the capacity of the thin HSS (Hollow Structural Sections) wall when supporting shear plate connections. The derivation is based on yield-line theory and the distribution of the yield lines within the web of the supporting girder. The obtained capacities agree with the experimental results and the failure mode investigations performed by Sherman and Ghorbanpoor [2]. Eq. (5) and the $k$-factor calculation procedure provide the connection capacity for the limit state of web mechanism in the supporting member.

\section{References}

[1] AISC (American Institute of Steel Construction). 2005.
Manual of Steel Construction. 13th ed. Chicago: AISC.

[2] Sherman, D. R., and Ghorbanpoor, A. 2002. Design of Extended Shear Tab. Final report for the AISC.

[3] Johanson, K. W. 1962. Yield-Line Theory. London: Cement and Concrete Association.

[4] Coelho, A. M. G., Bijlaard, F. S. K., and Kolstein, H. 2009. "Experimental Behavior of High-Strength Steel Web Shear Panels.” Engineering Structures 31: 1543-55.

[5] Hassanein, M. F. 2011. "Finite Element Investigation of Shear Failure of Lean Duplex Stainless Steel Plate Girders." Journal of Thin-Walled Structures 49: 946-73.

[6] Mashiri, F. R., and Zhao, X. 2002. "Plastic Mechanism Analysis of Welded Thin-Walled T-Joints Made up of Circular Braces and Square Chords under In-Plane Bending." Journal of Thin-Walled Structures 42: 759-83.

[7] Bakker, M. C. M. 1990. "Yield Line Analysis of Post-collapse Behavior of Thin-Walled Steel Members." Heron 35 (3): 1-50.

[8] Abolitz, A. L., and Warner, M. E. 1965. "Bending under Seated Connections." AISC Engineering Journal 2 (1): 1-5.

[9] Rahman, A., Mahamid, M., Akef, A., and Ghorbanpoor, A. L. 2007. "The Analyses of Extended Shear Tab Steel Connections Part I: The Unstiffened Connections." Engineering Journal 2: 117-32.

[10] Mahamid, M., Rahman, M., and Ghorbanpoor, A. 2007. "The Analyses of Extended Shear Tab Steel Connections Part II: The Stiffened Connections." Engineering Journal 2: 133-51.

[11] AISC (American Institute of Steel Construction). 1997. HSS (Hollow Structural Sections) Connections Manual. 1st ed. Chicago: AISC. 